\title{
What Impacts Young Generations' School/College Education Through the Lens of Family Economics? A Review on JFEI Publications in the Past Ten Years
}

\author{
Xiaohui Sophie Li ${ }^{1}$ (D)
}

Accepted: 8 October 2020 / Published online: 22 October 2020

(c) Springer Science+Business Media, LLC, part of Springer Nature 2020

\begin{abstract}
The purpose of this paper is to review a group of selected papers on the theme of education published in the Journal of Family and Economic Issues from the past 10 years to see what we have come to know regarding what impacted young generations' school/college education from the lens of family economics, as well as to share our thoughts on future directions to move the research inquiry forward. The paper first gives a brief description on all articles selected for this review. Followed by, a discussion of findings of these studies from the lens of macro-meso-micro analysis. Gaps in research ideas and methodology as well as future research directions are discussed in the end.
\end{abstract}

Keywords Education $\cdot$ School attendance $\cdot$ Educational outcomes $\cdot$ Youth $\cdot$ Family economics

Education is important because it offers the opportunity to gain knowledge and skills. Moreover, the process itself and the environment it creates facilitates young generations to gain perspectives of looking at life, to be competent in the global workforce, and to find ways to resolve conflicts and problems in the world. Governments have been investing more than ever before on education because they see its importance. Researchers also work diligently to identify factors impacting the attendance of formal educations, as well as the educational outcomes in hope to guide the policy and to make education more effective.

Educational psychologists study how children learn and the environmental contributes to children learning, primarily in educational settings. Social psychologists and scientists believe that individuals' thoughts, feelings and behaviors are influenced by others whom can be actual, imagined, or implied. They explain education attendance and outcomes as

This is one of several papers published together in Journal of Family and Economic Issues on the "Special Issue on Virtual Decade in Review".

Xiaohui Sophie Li

xli@niu.edu

1 School of Family and Consumer Sciences, College of Health and Human Sciences, Northern Illinois University, DeKalb, USA a result of the relation between mental state and social situations. In the family economics field, economic concepts such as production, resource distribution and decision making, are used to study the family. Children's education attendance and outcomes are considered as the outcome of family decision making as well as family resource distribution.

The purpose of this paper is to review articles published from the past 10 years in the Journal of Family and Economic Issues (JFEI), a journal focuses on the intricate relationship between the family and its economic environment, to examine what we now know regarding the theme of education through the lens of family economics, as well as to share our insights to identify what we do not know in hopes to move the research inquiry forward. First, we give a description on all articles selected for this review. Secondly, given that economic environment consists of all the factors in the immediate marketplace and the broader economy, we adopted the "level of analysis" approach in social science (Blalock 1979; Serpa and Ferreira 2019) to discuss the identified economic environment factors for educational attendance and outcomes by following the sequence of macrolevel, meso-level, and micro-level. We finished this review by addressing the gaps in research ideas and methodology as well as proposing ideas for future research.

Among all published articles in Volumes 31-40 of JFEI, sixteen of them were relevant to the theme of Education and therefore were chosen for this current review. The 
samples of the 16 studies came from many different countries/regions of the world including: Cambodia (1), China (2), Ghana (1), Latin American and Caribbean countries (1), Mexico (1), Sub-Saharan African countries (1), Taiwan (1), United States (7), and Uruguay (1). Most of the studies (14 out of 16) took the education related variables as the outcome/dependent variable. The other two studies addressed the impact of education - treating education as an independent variable. Most of the studies used existing data collected through surveys and all of the studies conducted quantitative data analyses to generate their results. Almost all studies investigated either school or college educational attainment and/or educational outcomes including school attendance, academic performance, language proficiency, years of schooling and so on. Next, we will discuss findings from these studies in hope to depict a picture of what we have known regarding what impacts the young generations' school/college educations.

Macro-meso-micro levels of social analysis have been widely used by the social science researchers to understand the world (DeCarlo 2018). Given the multi-faceted nature of education, as well as the different roles played by students, parents, schools, communities, governments, policy makers, and global economy in determining and achieving the effectiveness of education, it is helpful to use the "level of analysis" approach to help with drawing a relatively thorough picture of the economic environment factors related and determined. Our discussion will start by addressing the macro-level influence, then move to the meso-level influence, and end with micro-level influence.

\section{Macro-level Influence}

Macro-level analysis looks at the broadest systems, and it focuses on the impact of societal, political, legal, and economic forces. Among the sixteen articles selected for the theme of education, four of them addressed the possible macro-level influence on young generations' school/college education. These influences originated from political instability (Ouili, 2017), government policies (Lee 2012), and available funded programs (Meng and Pfau, 2012; Schochet and Johnson 2019).

By pulling data collected from sub-Saharan African countries, specifically Ivory Coast, Ouili (2017) proved the causal effect of Ivorian political instability on children's schooling and child mortality. More specifically, children who reached the official age to be enrolled in school within the period of the instability had a $10 \%$ lower probability of being enrolled in school; students who were attending school during the conflict experienced a more than 1-year lag in schooling attainment. Although there is only one article in this review that examined the influence of political instability and armed conflicts, it explicitly discussed the importance of peace in creating a stable social and economic environment for students to attend school and make educational progress on time.

China's one-child policy was examined by Lee (2012) and its way of impacting the gender equality in education in China. The researcher found that children in one-child households had significantly improved opportunities for education compared to children in multiple-child households, and the improvement of opportunity was especially greater for girls than boys. In other words, only-child girls had significantly better opportunities for education, which according to the author, contributed to greater educational gender equality in China. Many studies examining China's one-child policy have been mainly focused on its impact on population growth, unbalanced sex ratio, gender inequality, and the social and economic outcomes (Ebenstein 2010; Li et al. 2011; Lee 2012; Zhang 2017). However, the current study demonstrated that this policy had a positive impact on girls' educational opportunities given that no other child shared the family resources. The full impact of the policy might not be seen until many years after. More studies on the impact of existing policies from different angles could help to depict a better picture of the policies' real influence. In this case, the one-child policy indirectly influenced the family's resources management.

In this review, two studies focused on the influence of government simulation programs on children's school attendance, as well as young mothers' education outcomes. Meng and Pfau (2012) investigated the impacts of cash transfers on poverty and school attendance in Cambodia. They found that offering cash transfer to the poor populations could significantly reduce their poverty and improve their school attendance. Schochet and Johnson (2019) used data collected in the United States to ask whether child care subsidies increase maternal education level over time. Their results showed that subsidy receipt promoted mothers' educational attainment, with a larger impact found in mothers who received subsidies when their children were younger ( 2 years old vs preschool-age). Both the studies found that money simulation programs worked in promoting school attendance and educational attainment.

\section{Meso-level Influence}

Meso-level analysis looks at a specific group, community, or organization and it focuses on certain parts of a society. Among the sixteen articles selected for the theme of education, three of them focused on a specific group or community. One study examined immigrants at their time of arrival to the United States (Basu 2018). The second study focused on the fertility of parents with high education levels in Taiwan (Chen 
2016). The other study investigated the education financing of rural households in China (Wang and Moll 2010).

The timing of immigration can be quickly counted as a macro-level influencer because immigration itself is a big social movement, and the procedures and policies involved in immigration are out of the control of an individual or family or community. Immigration, however, also has an impact on the migrant community, making it an influence at the meso-level. By pulling a sample of siblings from the 2000 US Census, Basu (2018) examined the effects of late entry on the human capital of immigrant children, as well as the channels in which the age-at-migration affects the native-immigrant education gap. The author found that teenage entrants' educational outcomes were worse compared to younger entrants, as language proficiency had a mediating role on how age-of-arrival influenced education. Given that individuals and families cannot determine the time to arrive in the US, the author suggested that English language programs should be designed to help those children with late entry (ages 10 and above).

Seeing the declining fertility in Taiwan, Chen (2016) investigated the impact of parental education on fertility choice, as well as the effect of maternal and paternal education on fertility. The author found that increased parental education was a significant factor in reducing fertility, with maternal education having a stronger association with declining fertility. Most of the studies in the review tried to identify the factors which have an impact on education, while this is one of the studies that focused on the influence of having more education. This study offered us another perspective when more years of education are encouraged and promoted.

Wang and Moll (2010) addressed children's education financing alternatives among households in rural China. With the background knowledge that people in poor rural areas of China lack access to formal financial services, the researchers investigated ways that these families come up with the money to fund their children's school education. They found that private savings were the major source in financing education of children in school. They also concluded that the extension of financial services to children's education could motive parents to send their children for more education. This study also revealed that there was a substantial disparity in education expenditures among different educational levels. Higher education expenditures were barely self-supported, leading households into financial stress.

\section{Micro-level Influence}

Micro-level analysis looks at one-to-one interactions between individuals and it focuses on people's behaviors, relationships dynamics, as well as family environments.
Nine out of the sixteen articles for this review can be discussed as micro-level influencers as they focused on the impacts from family, parents, and individual themselves. In the following subsections, we will discuss the findings related to each type of influence one by one.

\section{Family Environment Influence}

It has been widely documented that family environment has a significant influence on children's social and behavior development as well as educational outcomes (HampdenThompson 2013; Razza et al. 2010; Sektnan et al. 2010). With parents' divorce and remarriage, the children's living arrangements grow diverse. More and more children are living in either single-parent or stepparent households (Cancian et al. 2014; Nielsen 2011). The family structure and children's living arrangements set up the difference where the family environment influence come into play. All three studies in this review examined how family structure and children's living arrangements influence children's educational attainment, educational progress, and their parental school involvement.

Cid and Stokes (2013)found that being raised in a nontraditional family was significantly linked with students' drop-out rate and falling behind in school, especially for boys. Myers and Myers (2015)also found that biological married parents had the highest levels of variety and frequency of involvement in children's school. Furthermore, examining data collected from Latin American and Caribbean countries, DeRose et al. (2017)found that children who lived with both biological parents or with only their biological mothers reported the best educational progress, compared to children with other living arrangements (lived apart from at least one biological parent or in a stepfamily). We can conclude from the findings of the three studies that living with both biological parents is the best for children's educational attainment and outcomes. Although the studies did not specify the financial aspects followed by family decisions and their living arrangements, it is very clear that two biological parents living together can generate better financial support for the children.

\section{Parental Influence}

Several aspects of parental influence were addressed in four articles of this review. According to the findings in this review, parental involvement, parenting style, parents' socioeconomic status (SES), and parents working hours could have an impact on children's educational and behavioral outcomes. How much parents are involved in children's education is seen as an important factor in improving children's academic achievements (Stacer and Perrucci 2013). Neymotin (2014)also reported that parental involvement in education had a positive 
impact on children's behavioral outcomes. The act of parenting is considered as one of the means through which parents can be involved in children education activities. Majumder (2016) explored the causal association between parenting styles and children's educational outcomes and found that the authoritative parenting style was most closely related to children completing more years of schooling and attaining a post-secondary degree.

Besides addressing parents' decisions and actions in children's education, parents' own working hours, education level, as well as other socioeconomic status factors were explored in determining how these have an impact on children's educational outcomes. In Neymotin (2014), income and family structure were used as control variables as the researcher believed this could be a factor in parental involvement. Stacer and Perrucci (2013) found that parents with less than a high school education were less involved with their children's education, and parents who worked more hours had less involvement in their children's school. Campos-Vazquez (2018) described how the socioeconomic status (SES) of parents related to the formation and development of skills of their teenage children. The author found that parental SES was related to children's skills, such that a higher SES was associated with increased cognitive skills and greater locus of control that promote and increase future SES.

\section{Self-Influence}

All of the discussions above addressed the external influence on young generations' educational attainment and outcomes. This section will cover the findings on internal influence or self-influence. Being self-motived or having intrinsic motivation is the key to academic achievement (Steinmayr et al., 2019). Savings and asset-accumulation are reflections of motivated financial behaviors. Two articles in this review focused on examining how youth's own financial behavior influences their educational outcomes. Ansong et al. (2019) investigated Ghanaian junior high students and suggested that experiencing asset-accumulation with an improved financial capability could lead to improved behavioral outcomes for school. Elliott et al. (2013) examined the role of assets on college progress among low-to-moderate income young adults and they found that those with college savings were more than three times as likely to be in college than those with no savings. Through these studies, we can see that motivated and self-disciplined financial behaviors are positively associated with educational success.

\section{Future Directions}

The present paper reviewed findings from sixteen published articles on the theme of education in the Journal of Family and Economic Issues from the past 10 years. To answer the question of what impacted the young generations' school/college education, the review discussed factors revealed from the sixteen studies on three level of analysis starting with macro-level influence, moving onto meso-level influence, ending with micro-level influence. Macro-level wise, both political stability and governmental policies and programs were found to have a significant impact on students' school attendance and educational attainment. At the meso-level, several specific groups or communities were explored. Those were immigrant communities in the United States, rural households in mainland China, and highly educated parents in Taiwan. Microlevel wise, family and parents as well as individuals' own behaviors were addressed in determining how they impact the children's educational outcome and achievements.

Despite these important findings published in the past 10 years, this author still sees that more research is needed to depict a bigger picture on what impacts the young generations' school/college education globally. First of all, we are living in a connected world. The change in global economy and the unforeseeable global health issues can have a huge and wide impact on parents' affordability of children' education, and the accessibility of students' schooling can be jeopardized. Coronavirus disease 2019 (COVID-19), first being reported in China late 2019, has spread to many countries in the world, and is considered by WHO to be a pandemic. The impact of this global health emergency is not limited to people who are suffering from this disease, or to people who are directly or indirectly associated with it or concerned about it. According to the United Nations Educational, Scientific, and Cultural Organization, education around the world has been disrupted as 191 countries closed schools, with $90.2 \%$ of the student populations affected as of April 22, 2020 (COVID-19 educational disruption and response.(2020)). Based on the data published by the Bureau of Labor Statistics in the United States, the unemployment rate caused by COVID-19 has reached historical records with 7.1 million Americans out of work as of March, 2020 (U.S. Department of Labor 2020). How this type of global health emergency impacts students and their educational accessibility and affordability is waiting to be addressed. With the impact of technology at different levels of education nowadays, especially facing the reality that most even all of the courseworks are offered virtually under this pandemic, some students from disadvantaged families are left behind. Besides, students with a parent who can facilitate the remote learning have better choice 
to succeed compared to those lack of supervisions due to parents' absence.

Regional or county-wide, political instability was discussed by one of the studies in this review. The author still thinks it is important to investigate how poverty and health disparity across countries or regions impact the young generations' educational accessibility and outcome nowadays to provide informed decisions for government and policy makers. The examination of more government programs in promoting educational outcomes should be conducted to determine if positive effects are generated from these programs (Meng and Pfau 2012; Schochet and Johnson 2019). As different results are found from different approaches to studies on existing policies, we would encourage more studies to be conducted to depict a better picture of policy's real influence on educational outcomes.

The exploration on what impacts the young generations' school or college education from meso-level analysis could be expanded significantly as we see different groups or communities are facing different barriers or difficulties in improving their children's education. Given that families and parents are still the most important influencers on a young person's life, in the following paragraph we will discuss more possible research directions from the micro-level. Family structure, together with children's living arrangement were examined on its way of impacting children's educational attainment and progress (i.e. Cid and Stokes, 2013). More factors under the umbrella of family environment can be explored as well, such as the siblings' dedication to education, and families' and relatives' values on education as family socialization that could shape a child's values and interest in school. Parents' SES were tested in studies in this review. We would encourage a focus on parents' traits that are associated with their own educational success, and can be cultivated or learned such as, diligence, grit, prioritizing, and delayed gratification. According to social learning theory (Bandura 1977), these values and beliefs can be passed on from generation to generation. Studies on financial socialization also proved parents can even pass along their financial literacy and financial capabilities to their children.

As we see the importance of parental involvement on children's educational outcomes, and the struggle parents are facing to reduce their children's media time, we would like to see how parental discipline on their children' school work and play time are connected with students' educational success. In the meanwhile, it is worthwhile to explore the different measures that schools are taking to attract students' interests and attentions in learning and how they are influencing students' educational outcomes. The connection between mental health, or conditions such as ADHD or autism, and educational experience has been addressed widely. We would like to see how a child's meaning seeking/finding tie to education and their values on education are connected to their educational success to continue the exploration on the importance of intrinsic motivation. Why the values and the meaning-making behaviors vary significantly among children should be explored as well, in hope to see how family, parents, communities, governments, and media can do their job in promoting the positive values and behaviors which can lead to educational success.

In the end, we want to encourage diverse approaches in methodology to study young generations' school choice and educational outcomes. Most of the reviewed studies published in the journal used existing dataset collected through surveys aimed to answer other research questions. It will be beneficial to design questionnaire/surveys based on the targeted research questions. Besides, collecting data through in-person interviews and conducting qualitative analyses based on the grounded theory could be valuable to present the unheard voices which cannot be collected through survey and quantitative analyses. It is also important to collect data from multiple informants including students, parents, as well as teachers to depict a more thorough picture of a student's attitudes, behaviors and performances in education.

Funding This study was not funded by any source.

Data availability This is a review paper based on published articles, no original data collection was involved.

\section{Compliance with ethical standards}

Conflict of Interest The author declares that she has no conflict of interest.

Ethical approval Not applicable.

Informed consent Not applicable.

\section{References}

Ansong, D., Chowa, G., \& Masa, R. (2019). Effects of youth savings accounts on school attendance and academic performance: evidence from a youth savings experiment. Journal of Family and Economic Issues, 40(2), 269-281. https://doi.org/10.1007/s1083 4-018-9604-5

Bandura, A. (1977). Social learning theory. New York: General Learning Press.

Basu, S. (2018). Age-of-arrival effects on the education of immigrant children: a sibling study. Journal of Family and Economic Issues, 39(3), 474-493. https://doi.org/10.1007/s10834-018-9569-4

Blalock, H. M. (1979). Social statistics. New York: McGraw-Hill.

Campos-Vazquez, R. M. (2018). Intergenerational persistence of skills and socioeconomic status. Journal of Family and Economic Issues, 39(3), 509-523. https://doi.org/10.1007/s 1083 4-018-9574-7

Cancian, M., Meyer, D. R., Brown, P. R., \& Cook, S. T. (2014). Who gets custody now? dramatic changes in children's living 
arrangements after divorce. Demography, 51(4), 1381-1396. https ://doi.org/10.1007/s13524-014-0307-8

Chen, I. C. (2016). Parental education and fertility: an empirical investigation based on evidence from Taiwan. Journal of Family and Economic Issues, 37(2), 272-284. https://doi.org/10.1007/s1083 4-015-9448-1

Cid, A., \& Stokes, C. E. (2013). Family structure and children's education outcome: evidence from Uruguay. Journal of Family and Economic Issues, 34(2), 185-199. https://doi.org/10.1007/s1083 4-012-9326-z

COVID-19 educational disruption and response. (2020, April 22). United Nations Educational, Scientific, and Cultural Organization. Retrieved from https://en.unesco.org/covid19/educationresponse

DeCarlo, M. (2018). Scientific inquiry in social work. Minneapolis, MN: Open Textbook Library.

DeRose, L. F., Huarcaya, G., \& Salazar-Arango, A. (2017). Children's living arrangements and on-time progression through school in Latin America and the Caribbean. Journal of Family and Economic Issues, 38(2), 184-203. https://doi.org/10.1007/s 1083 4-016-9502-7

Ebenstein, A. (2010). The "missing girls" of China and the unintended consequences of the one child policy. Journal of Human Resources, 45(1), 87-115. https://doi.org/10.1353/jhr.2010.0003

Elliott, W., Constance-Huggins, M., \& Song, H. (2013). Improving college progress among low- to moderate-income (LMI) young adults: The role of assets. Journal of Family and Economic Issues, 34(4), 382-399. https://doi.org/10.1007/s10834-012-9341-0

Hampden-Thompson, G. (2013). Family policy, family structure, and children's educational achievement. Social Science Research, 42(3), 804-817. https://doi.org/10.1016/j.ssresearch.2013.01.005

Lee, M. H. (2012). The one-child policy and gender equality in education in China: evidence from household data. Journal of Family and Economic Issues, 33(1), 41-52. https://doi.org/10.1007/s1083 4-011-9277-9

Li, H., Yi, J., \& Zhang, J. (2011). Estimating the effect of the one-child policy on the sex ratio imbalance in China: identification based on the difference-in-differences. Demography, 48(4), 1535-1557. https://doi.org/10.1007/s13524-011-0055-y

Majumder, M. A. (2016). The impact of parenting style on children's educational outcomes in the United States. Journal of Family and Economic Issues, 37(1), 89-98. https://doi.org/10.1007/s1083 4-015-9444-5

Meng, C., \& Pfau, W. D. (2012). Simulating the impacts of cash transfers on poverty and school attendance: the case of Cambodia. Journal of Family and Economic Issues, 33(4), 436-452. https:// doi.org/10.1007/s10834-012-9292-5

Myers, S. M., \& Myers, C. B. (2015). Family structure and schoolbased parental involvement: a family resource perspective. Journal of Family and Economic Issues, 36(1), 114-131. https://doi. org/10.1007/s10834-014-9409-0

Neymotin, F. (2014). How parental involvement affects childhood behavioral outcomes. Journal of Family and Economic Issues, 35(4), 433-451. https://doi.org/10.1007/s10834-013-9383-y

Nielsen, L. (2011). Shared parenting after divorce: a review of shared residential parenting research. Journal of Divorce \& Remarriage, 52(8), 586-609. https://doi.org/10.1080/10502556.2011.619913
Ouili, I. (2017). Armed conflicts, children's education and mortality: new evidence from Ivory Coast. Journal of Family and Economic Issues, 38(2), 163-183. https://doi.org/10.1007/s1083 4-016-9499-y

Razza, R. A., Martin, A., \& Brooks-Gunn, J. (2010). Associations among family environment, sustained attention, and school readiness for low-income children. Developmental Psychology, 46(6), 1528-1542. https://doi.org/10.1037/a0020389

Schochet, O. N., \& Johnson, A. D. (2019). The impact of child care subsidies on mothers' education outcomes. Journal of Family and Economic Issues, 40(3), 367-389. https://doi.org/10.1007/s1083 4-019-09628-0

Sektnan, M., Mcclelland, M. M., Acock, A., \& Morrison, F. J. (2010). Relations between early family risk, childrens behavioral regulation, and academic achievement. Early Childhood Research Quarterly, 25(4), 464-479. https://doi.org/10.1016/j.ecres q.2010.02.005

Serpa, S., \& Ferreira, C. M. (2019). Micro, meso and macro levels of social analysis. International Journal of Social Science Studies, 7(3), 120. https://doi.org/10.11114/ijsss.v7i3.4223

Stacer, M. J., \& Perrucci, R. (2013). Parental involvement with children at school, home, and community. Journal of Family and Economic Issues, 34(3), 340-354. https://doi.org/10.1007/s1083 4-012-9335-y

Steinmayr, R., Weidinger, A. F., Schwinger, M., \& Spinath, B. (2019). The importance of students' motivation for their academic achievement - Replicating and extending previous findings. Frontiers in Psychology. https://doi.org/10.3389/fpsyg.2019.01730

U.S. Department of Labor. (2020, April 3). The employment situation - March 2020. Bureau of Labor Statistics. Retrieved from https:// www.bls.gov/news.release/pdf/empsit.pdf

Wang, H., \& Moll, H. (2010). Education financing of rural households in China. Journal of Family and Economic Issues, 31(1), 353-360. https://doi.org/10.1007/s10834-010-9210-7

Zhang, J. (2017). The evolution of China's one-child policy and its effects on family outcomes. Journal of Economic Perspectives, 31(1), 141-160. https://doi.org/10.1257/jep.31.1.141

Publisher's Note Springer Nature remains neutral with regard to jurisdictional claims in published maps and institutional affiliations.

Xiaohui Sophie Li research interests have focused on investigation of diverse couple and family systems and their influence on children as well as cultural comparisons between Chinese and American couples and families. The overall goal of her scholarly activities is to help with understanding how couple and family systems influence the way children interpret the surrounding world and cope with daily stress and life crisis. She also aims to explore factors and programs to promote resilience and resourcefulness and to enhance family functioning and well-being. 